\title{
Research trends in healthcare and hospital administration in Japan: Content analyses of article titles in the Journal of the Japan Society for Healthcare Administration
}

\section{Yasutoshi Moteki ( $\nabla$ moteki@hiroshima-u.ac.jp )}

Hiroshima University

\section{Research Article}

Keywords: research trends, healthcare administration, hospitals, public medical insurance, content analysis, correspondence analysis, Japan

Posted Date: January 17th, 2022

DOI: https://doi.org/10.21203/rs.3.rs-1260856/v1

License: (c) (i) This work is licensed under a Creative Commons Attribution 4.0 International License. Read Full License 


\section{Abstract \\ Background}

To understand the characteristics and changes in research trends within various academic fields, research increasingly uses text mining, content analysis, or bibliometric methods. Such methods are widely used in medicine and medical policy to analyze trend changes over extended periods.

\section{Methods}

Using text-mining, this study quantitatively analyzed research trends in studies of healthcare administration in Japan, focusing on article titles over 28 years taken from the Journal of Japan Society for Healthcare Administration, known as Byon Kanri (Hospital Administration) from 1964 to 2007. Cooccurrence network and correspondence analysis were conducted to understand the changes in research interests during this period. To readily comprehend changing research trends over time in healthcare administration studies in Japan, a 10-year period division was set, resulting in three time periods. The correspondence analysis method analyzed the features and trends in research during each period.

\section{Results}

The configuration figures derived from the correspondence analysis revealed the first dimension revealed as an axis showing time transition and the second dimension as an axis showing policy/specific situations. The extracted words displayed in the configuration maps at the intersection of the two axes were the patient, survey, and evaluation. They had no distinctive features compared to the other words and were commonly used in the titles of articles in this journal, regardless of the period.

\section{Conclusions}

The text data analysis throughout the period shows the characteristics of and changes in the research trends in healthcare and hospital administration in Japan. Many points were clarified by this paper. First, the changes in the geriatric care system of public medical insurance and the related introduction of the long-term care insurance system in 2000 are also expressed in the characteristic extracted words expressed in the co-occurrence network analysis and correspondence analysis. Second, references to the role of doctors, nurses, and other health care professionals during the 14 years after the journal name change were frequent in studies, presenting extracted words such as doctors, staff, nurses, nursing, managers, roles, and relationships. The chi-square test focusing on these extracted words and the period classification confirmed a statistically significant relationship between them.

\section{Background}


The global spread of novel coronavirus infections since 2019 has provided an opportunity for researchers and practitioners in the healthcare field to challenge and reconsider the appropriateness of previous healthcare policies and hospital management practices. In Japan, the core functions of community healthcare have long been performed by public hospitals run by local governments. However, since the 1990s, economic constraints and a subsequent deterioration in national and local government finances have led to a reduction in the number of public hospitals, a reduction in the number of hospital beds, and a change in management methods from direct management to greater control by local independent administrative agencies. In the midst of the current global coronavirus pandemic crisis, the importance of organizational flexibility and the need to improve the working conditions of medical personnel, including doctors, nurses, and clinical engineers who operate ventilators and extracorporeal membrane oxygenation, as well as ensuring stable availability of personnel, have become important issues. In this context, it is important to reflect on changes in research trends to date in healthcare administration related to the efficient management of hospitals and hospital organizations in order to consider and implement future healthcare policy and management more effectively.

This study examined the changing trends in healthcare administration research in Japan using content analysis or text-mining methods. Since the 1980s, a method of content analysis has been proposed by Krippendorf [1], followed by Muskens [2], Fields [3], and Scherl and Smithson [4], focusing on the symbolism and meaning of documents and texts. With the development of analytical technology and the increase in available software, the number of studies applying text mining methods has increased. The text-mining analysis used in this study targeted article titles in the Journal of the Japan Society for Healthcare Administration (Nihon Byoin Kanri Gakkai-shi). The journal was called Byoin Kanri (Hospital Administration) from 1964 to 2007 . From 2008 onwards, when the name of the society changed, the name of the journal also changed to the current one.

The targetted volumes for text mining ranged from volume 35(1), published in 1994, to volume 58(4), published in 2021. The volume numbers are given through the two journal names, which changed simultaneously with the name of the society. The text-mining method is an enhanced version of content analysis, which focuses on symbolic phenomena and semantic content in much social research work. Krippendorff defines content analysis as "a research technique for making replicable and valid inferences from data to their context" ([1] p21). With the development of computer technology, it has become possible to process greater amounts of content-related data, and this technique is often referred to as text mining. Researchers can also use the same open data generated to perform additional tests and reproduction studies, leading to more scientifically rigorous assessments to ensure verifiability.

In 1961, Japan's medical insurance system became universal, with all citizens covered by the public medical insurance system. The former Health Insurance Law, enacted in 1922 during the Taisho era (1912-1926), only insured manual laborers whose remuneration was below a certain amount in certain institutions with 10 or more employees. Later, in 1938, during the Showa era (1926-1989), a revised National Health Insurance Law was enacted, but since enrollment was voluntary for both institutions and individuals, many citizens were not covered. Following a further revision of the National Health Insurance 
Law in 1958 and the implementation of universal health insurance in 1961, the public health insurance system has basically remained unchanged, which differs greatly from the situation in the United States and other similar countries where people mainly subscribe to private medical insurance. However, two major changes have been introduced to this public insurance system, namely, the Health Care Law for the Elderly in 1983 and the Long-Term Care Insurance Law in 1997, which were in response to the rapid increase in the cost of medical care for older adults due to the aging of society in Japan.

This study analyzed changing trends in healthcare administration research in Japan using text-mining methods in relation to article titles of the Nihon Iryo Byoin Kanri Gakkai-shi (Journal of the Japan Society for Healthcare Administration). In the field of healthcare management and medicine, the following are some of the studies that use bibliometrics to analyze research trends [5-9]. Some [5-7] review the research trends on new coronavirus infections by bibliometric analysis. Identifying research trends using bibliometric data is important in terms of facilitating and positioning the next individual, original research. The text mining analysis used in this paper is also part of the research methods using bibliometric data.

\section{Japan's universal health insurance system and changes in the health care system with the introduction of the long-term care insurance system}

As noted, Japan's public medical insurance system provides cover for all citizens. The Japanese Ministry of Health, Labor and Welfare (MHLW) states that Japan's public medical insurance system has the following four characteristics: (1) all citizens are covered by public medical insurance, (2) all citizens can freely choose medical institutions (free access); (3) advanced medical care is provided at a low cost; and (4) public funds are invested to maintain universal coverage, while the system is based on social insurance [10].

The Japanese public health care system has developed in response to ongoing economic challenges and the rapid aging of the population following an earlier period of high economic growth post-World War II. According to the definitions of the United Nations and the World Health Organization, a society with an aging rate of more than $7 \%$ is called an aging society, with more than $14 \%$ is called an aged society, and with more than $21 \%$ is called a super-aged society [11]. The aging rate in Japan has continued to rise, reaching the stage of an aging society in 1970, an aged society in 1994, and a super-aged society in 2007. First, and in response to this evolving situation, the 1983 Health Care Law for the Elderly abolished the system of free medical care for those aged 70 years and over (replacing the previous system of free medical care for older adults, operating since 1973). Furthermore, medical insurance subscribers aged 75 years and over ( 65 years and over for those with disabilities above a certain level and certified under the Health Care Law for the Elderly) were classified separately from those insured under that age. The medical care system for older adults in these age groups is funded by public expenditure (derived from taxation) and contributions from various medical insurance systems, including public employee mutual aid societies (Kyosai Kumiai) and the health unions of general companies (Kenko Hoken Kumial). The Long-Term Care Insurance Law, passed in 1997 and into effect in 2000, aimed to separate nursing care 
benefits from the medical care system, where medical insurance covered nursing care for the elderly in convalescent beds in geriatric care, as symbolized by "social hospitalization." It established a public nursing care insurance system with those over 40 as insured and the basic local governments as the insurer to clarify cost-sharing and benefits, and at the same time, secure financial resources for nursing care [12]. The introduction of the long-term care insurance system in 2000, like the abolition of the free medical care system for the elderly in the 1983 amendment to the Health Care Law for the Elderly, was a systemic reform to cope with the expansion of medical costs associated with the aging of society.

A further change was introduced concerning late-stage medical care for older adults in 2008 . The elderly aged 75 and over are enrolled in an independent late-stage medical care system operated by a regional federation (of which the basic municipalities are members) and receive medical benefits [13]. Finally, the 2015 Medical Insurance Reform Law resulted in the expansion of financial support for the national health insurance system, a gradual increase in the cost of meals at the time of hospitalization, and the introduction of a fixed fee for visits to large hospitals without a referral.

\section{Statistical analysis of research trends in Japanese healthcare administration studies}

In this section, the selection process for target journal determination in applying text mining analysis of research trends is presented. The following data on academic societies were derived from the Gakkai Meikan database of the Science Council of Japan, the Japan Science Support Foundation, and the Japan Science and Technology Agency (https://gakkai.jst.go.jp/gakkai/). The database was last updated on March 19, 2021, with results based on the fiscal year 2020 survey of academic societies.

Sato [14] lists 10 Japanese academic organizations related to hospital management: (1) the Japanese Society of Medical Science, (2) the Japanese Society of Internal Medicine, (3) the Japanese Association of Surgeons, (4) the Japanese Society for Healthcare and Hospital Administration, (5) the Japanese Society of Nursing Science, (6) the Japanese Society for Nursing Administration, (7) the Japanese Society for Health Care Management, (8) the Japanese Society for Clinical Pathology, (9) the Japanese Society for Medical Work Assistance, and (10) the National Association of Medical Affairs Research. Data concerning the first seven of these are available in the Gakkai Meikan database. The Japanese Society of Medical Science is an umbrella society for medical research, with the second, third, and fourth organizations listed being registered as subcommittees within it. Only the fourth and seventh organizations listed specifically target medical and hospital administration in general, including nursing administration. Table 1 summarizes the characteristics of these two societies based on the Gakkai Meikan database.

Concerning these two academic societies presented in Table 1, this study chose to focus on the Journal of the Japan Society for Healthcare Administration, as the society involved has been in existence longer and its related journal has the longest publishing history in the field; therefore, it was considered likely to provide a clearer picture of changing academic research trends over time. 
Table 1

Academic associations concerned with healthcare administration studies in Japan

\begin{tabular}{|c|c|c|c|c|c|}
\hline $\begin{array}{l}\text { Name of } \\
\text { association }\end{array}$ & $\begin{array}{l}\text { Establishment } \\
\text { date }\end{array}$ & $\begin{array}{l}\text { Name of the journal } \\
\text { the association } \\
\text { publishes }\end{array}$ & $\begin{array}{l}\text { Number of } \\
\text { members } \\
\text { (individuals) }\end{array}$ & $\begin{array}{l}\text { Number } \\
\text { of } \\
\text { members } \\
\text { (legal } \\
\text { entities) }\end{array}$ & $\begin{array}{l}\text { Is the } \\
\text { society } \\
\text { affiliated } \\
\text { with the } \\
\text { Japanese } \\
\text { Medical } \\
\text { Association? }\end{array}$ \\
\hline $\begin{array}{l}\text { Nihon Iryo } \\
\text { Byoin Kanri } \\
\text { Gakkai (Japan } \\
\text { Society for } \\
\text { Healthcare } \\
\text { Administration) }\end{array}$ & April 3, 1968 & $\begin{array}{l}\text { Until 2007, from } \\
\text { 1964, the journal } \\
\text { was named Byoin } \\
\text { Kanri (Hospital } \\
\text { Administration). } \\
\text { From } 2008 \\
\text { onwards, it is called } \\
\text { the Journal of the } \\
\text { Japan Society for } \\
\text { Healthcare } \\
\text { Administration }\end{array}$ & $\begin{array}{l}1490 \\
\text { (regular } \\
\text { member) }\end{array}$ & - & $x$ \\
\hline $\begin{array}{l}\text { Nihon Iryo } \\
\text { Management } \\
\text { Gakkai (Japan } \\
\text { Society for } \\
\text { Health Care } \\
\text { Management) }\end{array}$ & $\begin{array}{l}1998 \text { (Launch } \\
\text { of the } \\
\text { predecessor } \\
\text { Critical Path } \\
\text { Study Group) }\end{array}$ & $\begin{array}{l}\text { Journal of Japan } \\
\text { Society for Health } \\
\text { Care Management } \\
\text { (from 2000) }\end{array}$ & 7900 & 13 & \\
\hline
\end{tabular}

\section{Related studies}

As noted, content analysis or text mining methods are increasingly used to analyze research trends in academic journals. Examples in various fields are discussed in Moteki [15]. While Krippendorff [1] pioneered the content analysis method, Alcaide-Muñoz et al. [16] developed a quantitative method, namely, a science-mapping approach, to identify research trends in the field of local governments. Their research applied a bibliometric approach across e-government fields to visualize research trends and classify relevant studies by building a strategic map and an evolution map. The text-mining method used in this study also allows for the visualization of relevant characteristics and changes in research trends using correspondence analysis and co-occurrence network analysis.

In the medical field, Adunlin et al. [17] conducted a system analysis and bibliometric analysis of research trends. Hao et al. [18] also used text mining methods to conduct a bibliometric analysis of medical research trends. Khalil and Gotway Crawford [19] conducted a bibliometric analysis of behavioral risk factor surveillance studies in the United States. In the field of public administration, which is a related field of medical administration, Ni et al. [20] applied the bibliometric method to identify research trends in administrative studies published in the Public Administration Review in relation to the United States. They selected 3,934 articles from the Public Administration Review and analyzed bibliometric data focusing on author attributes, showing the word count results of the top 50 words most frequently used in the titles 
during three target time periods. Many other bibliometric studies have also used the Public Administration Review as an object of analysis [21-24]

\section{Materials And Methods}

\section{Collection of materials}

This study quantitatively examined research trends in hospital administration studies after the 1980s in Japan using the titles of articles published in the Journal of the Japan Society for Healthcare Administration, ranging from volume 35(1), in 1994, to volume 58(4), in 2021. A total of 28 years, including 14 years each before and after the change in journal name from 2008 (the new name applied from volume 45(1) onwards), were covered for the analysis.

The article titles from the Journal of the Japan Society for Healthcare Administration were gathered to determine post-war research trends in hospital administration studies in Japan. The search results were saved as Excel spreadsheet files in a tab-separated values (TSV) format, which was arranged by separating each data point by tab characters (implemented on November 28, 2021). As the CiNii Articles database only contains volumes from 1995, articles from four issues of volume 35 in 1994 were inputted by the author and added to the dataset, based on the tables of contents of originally published journals. The table of contents information provided by the National Diet Library for the journal was used to check the accuracy of the journal titles. The data from volume 35 to volume 58 were consolidated into one dataset file in Excel spreadsheet format. The dataset file was translated using the Google Translate application from Japanese to English. Machine translation was used for the dataset to facilitate replication and follow-up research by third-party researchers. The author read the entire translated text, confirming the appropriateness of the machine translation.

The author then made the following modifications to the dataset file: (1) titles including "Preface," "Editor's Postscript," "Special Remarks," "Special Lectures," "Annual Meeting," "Inauguration of the President," and "General Contents," as well as "book reviews" were omitted; and (2) non-research articles with blank author names that usually comprised administrative communication articles concerning the association and annual conferences were also omitted. The final dataset comprised 692 articles from the journal.

To analyze the text data of the articles from the journal, KH Coder (version 3.Beta.04a) produced by Dr. Koichi Higuchi of Ritsumeikan University was selected because it is free to use and has advanced visualization features in terms of conducting correspondence analysis. Higuchi [25] provides details concerning the software and provides an application example for real text materials. $\mathrm{KH}$ Coder offers a choice of several methods for processing English extracted words, and the Stanford POS Tagger was chosen for morphological analysis of sentences (this option is the default for KH Coder).

\section{Results}


For the text analysis, the dataset was loaded into $\mathrm{KH}$ Coder, and the extracted words were pre-processed using Stanford POS Tagger. The author conducted correspondence analysis and co-occurrence network analysis to graphically depict the relationships between the extracted words. By drawing configuration maps as revealed in the correspondence analysis with 10-year periods as external variables, the changes in and characteristics of each period in terms of healthcare administration studies in Japan can be visualized.

\subsection{Co-occurrence network analysis}

Co-occurrence network analysis was performed to understand the change in focus before and after the change in the journal name from January 2008. The year 2008 saw the introduction of the late-stage medical care system for older adults and a trend toward separating the elderly care component within public medical insurance and a greater injection of public funds. Using the two periods before and after the change in the public medical insurance system in 2008 was considered likely to facilitate a greater understanding of differing research trends during the pre- and post-2008 periods. The co-occurrence network analysis with 60 filtering edges is shown in Figure 1. This study used the Jaccard index to determine the selection criteria [26] provides a detailed mathematical explanation of the Jaccard index). The Jaccard index is the default option for KH Coder.

The words insurance, elderly, and long-term were extensively used in the journal prior to January 2008 (see the left side of Figure 1). The use of these words refers to the introduction of a new healthcare system for older adults in 1998, which was actively discussed at conferences and published papers. Conversely, we found extensive use of the extracted words prefecture, relationship, change, future, safety, and doctor, among others, for the period after March 2000 (see the right side of Figure 1). The use of the word prefecture refers to changes following the devolution of authority from prefectures to municipalities in line with the Decentralization Act from 2000. The impact of decentralization reforms, including in the healthcare sector, seemed to have affected research trends in healthcare administration. The extracted words care, medical, hospital, evaluation, management, patient, nurse, examination, system, and quality, commonly featured in studies of healthcare administration in Japan throughout the two periods, as shown in their predominance at the center of Figure 1.

\subsection{Correspondence analysis}

In this section, the relationship between the extracted words is examined using the correspondence analysis method, which facilitates a graphical display of categorical data. A 10-year period was set as an external variable. Three 10-year periods were used to display relevant characteristics and changes in healthcare administration studies over time in Japan. The final two years, 2020-2021, were included in the preceding period, 2010-2019, because 2020-2021 was otherwise too short. To facilitate verification research by other researchers, the author did not limit the target focus in this study as narrowing the target parts of speech or excluding certain extracted words can inhibit conducting correspondence 
analysis. For this reason, extracted words unrelated to the research theme, such as the slash symbol, are shown in the subsequent analysis results.

The results of the correspondence analysis based on the three periods are presented in Figure 2 . The extracted words located near the origin where the first and second dimensions intersect, such as survey, patient, and evaluation, had no distinctive features compared to the other words. These words are often used regardless of the time period and are characteristic of the diachronic research trends in this field. The most influential axis from left to right was the time dimension in the configuration map (the contribution ratio was $65.16 \%$ ). The words welfare, classification, hospitalization, and university appeared in the upper left quadrant of Figure 2, near the 1994-1999 display. The use of these extracted words is related to the contents of studies conducted between 1994 and 1999. The words nurse, Japan, staff, management, and safety appeared on the right side of the configuration map, near the 2010-2021 display. In Figure 2, the chronological indication with a black background presents the variables of the time periods (white on black) of 1994-1999, 2000-2009, and 2010-2021 in a left-to-right time transition pattern.

We found that the words doctor, manager, cost, acute, insurance, service, satisfaction, and condition appeared at the lower part of Figure 2, near the 2000-2009 display. The word acute forms part of the expression "severe acute phase" and is used in relation to the type of hospital involved (the English title of Yoshida, et al. [27] includes the phrase "severe acute pancreatitis." The severe acute phase is called Kyuuseiki in Japanese and is used in combination with the chronic phase, known as Manseiki in Japanese). Differences in the values of dimension 2 are expressed as differences in positioning between the top and bottom of Figure 2. The word plan was located at the highest position, and extracted words related to medical policy, such as university and hospitalization, were also found in the upper part of Figure 2. In the lower part of Figure 2, the words accidents, emergencies, and discharges appeared, indicating types of policy and specific situations in hospitals. Dimension 2 can be considered an axis representing certain policy/specific situations.

The extracted words located in the earlier period had no distinctive features compared to the other words. The extracted words displayed in the configuration map at the intersection of the two axes, around the center of Figure 2, were the patient, survey, and evaluation, which were commonly used words in the titles of articles published in this journal, regardless of the time period.

The words doctors, staff, nurses, nursing, managers, roles, and relationships, which relate to the occupations, roles, and interrelationships of medical professionals, were tagged in order to include them together in subsequent analyses. Table 2 shows a cross-tabulation in relation to whether the title of each article included or did not include these tagged extracted words and the two periods (pre- and post-2008) by journal name. $\mathrm{A} \chi^{2}$ test conducted in relation to the data presented in this table showed a chi-square value of 3.87 , indicating a statistically significant association between the two variables at the $5 \%$ level. 
Table 2

Target words included or not included pre- and post-2008 in the journal

\begin{tabular}{|lllc|}
\hline & $\begin{array}{l}\text { Included } \\
(\mathbf{1})\end{array}$ & $\begin{array}{l}\text { Not included } \\
(\mathbf{0})\end{array}$ & 382 \\
\hline $\begin{array}{l}\text { Journal of the Japanese Society on Hospital Administration } \\
\text { (pre-2008) }\end{array}$ & 68 & 314 & $100.0 \%$ \\
\hline row \% & $17.8 \%$ & $82.2 \%$ & 310 \\
\hline Journal of the Japan Society for Healthcare Administration & 74 & 236 & 692 \\
\hline row \% & $23.9 \%$ & $76.1 \%$ & $100.0 \%$ \\
\hline & 142 & 550 & \\
\hline
\end{tabular}

\section{Discussion}

Using text-mining, this study quantitatively analyzed research trends in studies of healthcare administration in Japan in relation to article titles over 28 years taken from the Journal of the Japan Society for Healthcare Administration. The author conducted co-occurrence network analysis and correspondence analysis to understand the changes in research interests during this period. In the correspondence analysis, with three 10-year periods set as an external variable, the first dimension of the configuration figures was identified as an axis of time transition, and the second dimension concerned policy/specific situations, in terms of the placement of extracted words in the configuration map. The extracted words located in the earlier period had no distinctive features compared to the other words. The extracted words displayed in the configuration map at the intersection of the two axes, around the center of Figure 2, were the patient, survey, and evaluation, which were shown to be commonly used words in the titles of articles published in this journal, regardless of the time period.

\section{Conclusion: Implications Of This Study And Future Research Agendas}

This study is novel in that it analyzed research trends in healthcare administration or hospital administration management in Japan using quantitative methods, and clarified relevant diachronic characteristics and changes over time. Through co-occurrence network analysis and correspondence analysis, changes in research trends in academic societies could be identified that corresponded with changes in Japan's public medical insurance system.

One limitation of this study is that it covered only a certain period of time in a single journal. A similar analysis of other journals would help validate the results of this study's analyses and simultaneously clarify potentially differing research trends among the various academic societies and associations. 
Specifically, we intend to analyze the Journal of the Japan Health Care Management, for comparison. In addition, quantitative analysis has certain limitations. Text mining analysis of journal article titles focuses on the frequency of extracted words in the titles of the articles. It is possible that studies with infrequently used words but which have a decisive impact could be overlooked. While it is important for the academic community to accumulate individual empirical studies, it is also important to review past changes in research trends to facilitate an understanding of how various issues have influenced academic development. The author hopes that the publication of this study will contribute to a collaborative academic dialogue on understanding changing trends in healthcare administration research in Japan.

\section{Declarations}

\section{Ethics approval and consent to participate}

This is not a study of humans and thus does not require ethical approval concerning data gathering.

\section{Consent for publication}

This is not a study of humans and thus does not need to require participants' consent for publication.

\section{Availability of data and materials}

The datasets generated and/or analyzed during the current study are not publicly available due to the usage of a public database copyrighted by a third-party Japanese government agency. The aggregated statistics of each question item are available from the corresponding author upon reasonable request. In addition, the details of the procedure for creating the dataset are clearly explained in the manuscript to ensure that third-party researchers can conduct follow-up tests.

\section{Competing interests}

The author declares no potential conflicts of interest with respect to the research, authorship, and/or publication of this article.

\section{Funding}

This work was supported by a subsidy for English editing services provided by the affiliated university.

\section{Authors' contributions}

This is a single-authored paper.

\section{Acknowledgments}




\section{References}

1. Krippendorff K. Content Analysis: An Introduction to its Methodology. Thousand Oaks: Sage; 1980.

2. Muskens G. Mathematical analysis of content. Qual Quant. 1985;19:99-103. https://doi.org/10.1007/BF00188651.

3. Fields EE. Qualitative content analysis of television news: Systematic techniques. Qual Sociol. 1988;11:183-93. https://doi.org/10.1007/BF00988954.

4. Scherl LM, Smithson M. A new dimension to content analysis: Exploring relationships among thematic categories. Qual Quant. 1987;21:199-208. https://doi.org/10.1007/BF00167608.

5. Ram S. Coronavirus research trends: A 50-year bibliometric assessment. Sci Technol Libr. 2020;39:210-26. https://doi.org/10.1080/0194262X.2020.1742270.

6. Verma S, Gustafsson A. Investigating the emerging COVID-19 research trends in the field of business and management: A bibliometric analysis approach. J Bus Res. 2020;118:253-61. https://doi.org/10.1016/j.jbusres.2020.06.057.

7. Zhang J, Yu Z, Zhao B, Sun R, Vejre H. Links between green space and public health: A bibliometric review of global research trends and future prospects from 1901 to 2019. Environ Res Lett. 2020;15, 063001. https://iopscience.iop.org/article/10.1088/1748-9326/ab7f64/meta.

8. Merigó JM, Núñez A. Influential journals in health research: A bibliometric study. Global Health. 2016;12:46. https://doi.org/10.1186/s12992-016-0186-4.

9. Milat AJ, Bauman AE, Redman S, Curac N. Public health research outputs from efficacy to dissemination: A bibliometric analysis. BMC Public Health. 2011;11:934. https://doi.org/10.1186/1471-2458-11-934.

10. Ministry of Health, Labour and Welfare. Nihon no iryo hokenseido ni tsuite [The medical insurance system in Japan]; 2018. https://www.mhlw.go.jp/content/12400000/000377686.pdf.

11. Baba S. The super-aged society. World Health. 1993;46:9-11. https://apps.who.int/iris/bitstream/handle/10665/326201/WH-1993-May-Jun-p9-11-eng.pdf.

12. Ministry of Health, Labour and Welfare. Kaigo hokenseido no gaiyo [Outline of long-term care insurance system in Japan]; 2021. https://www.mhlw.go.jp/content/000801559.pdf.

13. Ministry of Health, Labour and Welfare. Kokikoreisha Iryoseido ni tsuite [the medical system for the elderly]; 2016. https://www.mhlw.go.jp/bunya/shakaihosho/iryouseido01/info02d-35.html.

14. Sato Y. Gakkai soshiki [Outline of society organization for hospital management]. In: Byoin no shikumi/ kakushu dantai, gakkai no naritachi [Structure of hospital / Organization of various organizations and academic societies]. Kimura N, editor. Tokyo: Nihon Iryokeiei Kikaku; 2017. p. 117-26.

15. Moteki Y. Research trends in local autonomy studies in Japan: Text analyses of article titles in the journal of urban management and Local Government research. Chihoujichi Kenkyu [J Urban Manag Local Gov Res]. 2021;36:1-14. 
16. Alcaide-Muñoz L, Rodríguez-Bolívar MP, Cobo MJ, Herrera-Viedma E. Analysing the scientific evolution of e-government using a science mapping approach. Gov Inf Q. 2017;34:545-55.

17. Adunlin G, Diaby V, Xiao H. Application of multicriteria decision analysis in health care: A systematic review and bibliometric analysis. Health Expect. 2015;18:1894-905. https://doi.org/10.1111/hex.12287.

18. Hao T, Chen X, Li G, Yan J. A bibliometric analysis of text mining in medical research. Soft Comput. 2018;22:7875-92. https://doi.org/10.1007/s00500-018-3511-4.

19. Khalil GM, Gotway Crawford CAG. A bibliometric analysis of U.S.-based research on the behavioral risk factor surveillance system. Am J Prev Med. 2015;48:50-7. https://doi.org/10.1016/j.amepre.2014.08.021.

20. Ni C, Sugimoto CR, Robbin A. Examining the evolution of the field of public administration Through a bibliometric analysis of public administration review. Public Admin Rev. 2017;77:496-509 https://doi.org/10.1111/puar.12737.

21. Gooden ST. PAR's social equity footprint. Public Admin Rev. 2015;75:372-81.

22. Groeneveld S, Tummers L, Bronkhorst B, Ashikali T, Van Thiel S. Quantitative methods in public administration: Their use and development Through time. Int Public Manag J. 2015;18:61-86 https://doi.org/10.1080/10967494.2014.972484.

23. Perry JL, Kraemer KL. Research methodology in the Public Administration Review, 1975-1984. Public Admin Rev. 1986;46:215-26 https://doi.org/10.2307/3110436.

24. Jones WA Jr, Doss CB Jr. Contributions to the public administration review: 1966-1975. Public Admin Rev. 1977;37:270-5 https://doi.org/10.2307/974822.

25. Higuchi K. A Two-step Approach to Quantitative Content Analysis: KH Coder Tutorial using Anne of Green Gables (part I). Ritsumeikan Soc Sci Rev. 2016;52:77-91.

26. McCormick WP, Lyons NI, Hutcheson K. Distributional properties of Jaccard's index of similarity. Commun Stat Theor Methods. 1992;21:51-68 https://doi.org/10.1080/03610929208830764.

27. Yoshida M, Takada T, Kawarada Y, Hirata K, Mayumi T, Sekimoto M, et al. Health insurance system and payments provided to patients for the management of severe acute pancreatitis in Japan. J Hepatobil Pancreat Surg. 2006;13:7-9. https://doi.org/10.1007/s00534-005-1046-4.

\section{Figures}




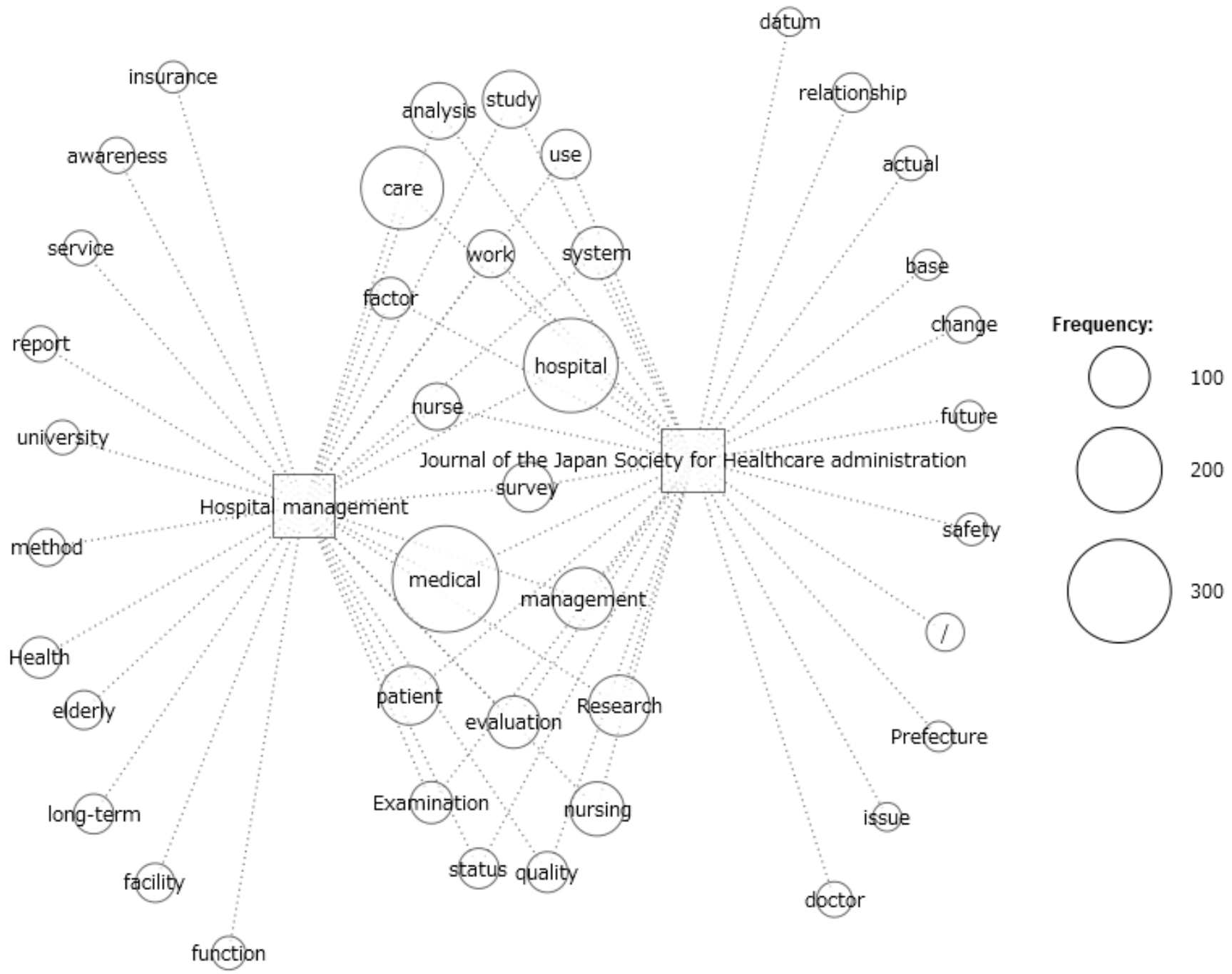

Figure 1

Co-occurrence network analysis of the extracted words 


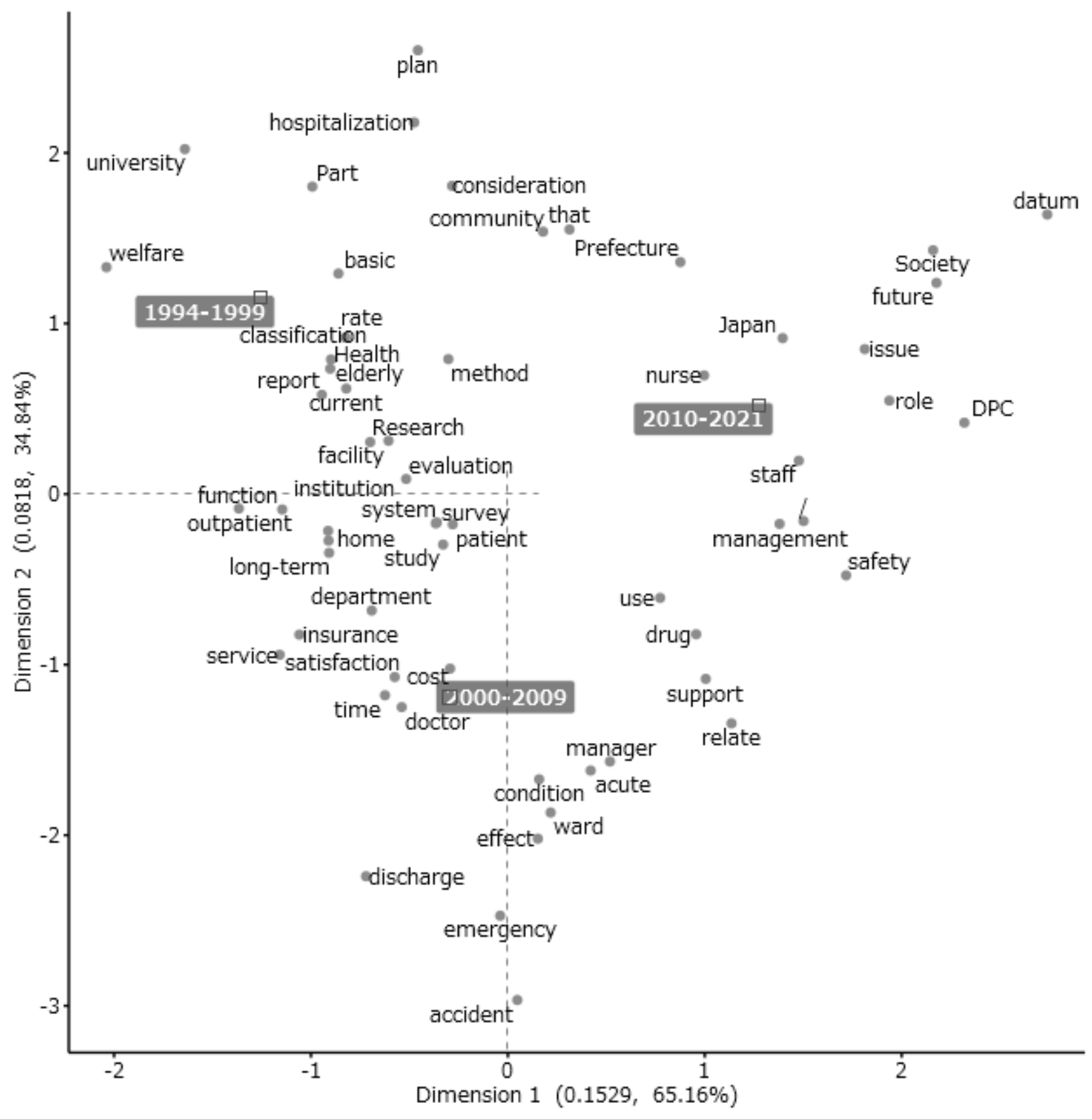

Figure 2

Correspondence analysis (dimension 1 [time] and dimension 2 [policy/specific situations]) 